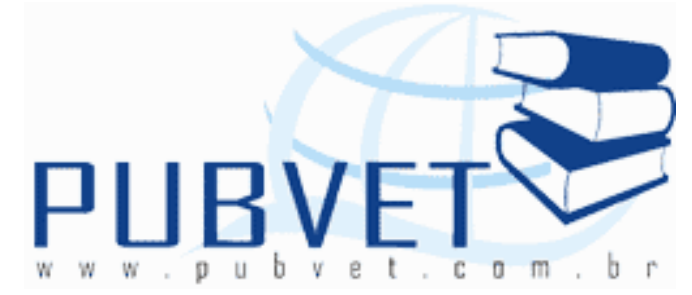

PUBVET, Publicações em Medicina Veterinária e Zootecnia.

\title{
Esofagotomia cervical em Tartaruga-da-Amazônia Podocnemis expansa Schweigger, 1812 (Testudines - Podocnemididae)
}

André Luiz Quagliatto Santos ${ }^{1}$, Eloisa Paula Santana ${ }^{3}$, Rogério Rodrigues de Souza ${ }^{2}$, Caio Henrique Ferreira ${ }^{2}$, Lorena Tannús Menezes ${ }^{2}$, Sérgio Rodrigo Pereira de Oliveira ${ }^{2}$, Liliane Rangel Nascimento ${ }^{2}$, Mariana Batista Andrade ${ }^{4}$

Laboratório de Ensino e Pesquisas em Animais Silvestres - LAPAS, FAMEV/UFU, e-mail: quagliatto@famev.ufu.br 1. Docente. 2. Mestrandos. 3. Médica Veterinária Autônoma. 4. Doutoranda.

\section{Resumo}

Este estudo propõe uma técnica de esofagotomia cervical em Podocnemis expansa, uma tartaruga amazônica de hábitos aquáticos. Os animais, pertencentes ao Laboratório de Pesquisa em Animais Silvestres da FAMEV-UFU, foram submetidos à anestesia com propofol na dose de $10 \mathrm{mg} / \mathrm{Kg} / \mathrm{I}$.V.. A técnica cirúrgica consistiu de incisão de pele na região cervical ventral mediana de aproximadamente $4 \mathrm{~cm}$, afastamento dos músculos cervicais ventrais e traquéia, incisão na parede ventral do esôfago e sutura simples contínua do esôfago e da musculatura e simples separada da pele com fios categute 3-0 cromado e nylon 3-0, respectivamente. Valores de hemoglobina e volume globular foram avaliados antes e após a cirurgia. Os animais foram submetidos à pesagens diárias e à administração de enrofloxacina na dose de $5 \mathrm{mg} / \mathrm{Kg} / \mathrm{I}$.M. durante 3 dias após a cirurgia. A retirada dos pontos de pele se deu com 16 
dias de pós-cirúrgico. Conclui-se que a técnica ora proposta mostrou-se eficaz na sua execução, bem como proporcionou recuperação satisfatória dos animais.

Palavras-chave: esofago, técnica cirúrgica, répteis.

\title{
Cervical esophagectomy of Amazon river turtle Podocnemis expansa Schweigger, 1812 (Testudines - Podocnemididae)
}

\begin{abstract}
This study proposes a technique of cervical esophagectomy Podocnemis expansa, an Amazonian river turtle aquatic habitat. The animals belonging to the Research Laboratory of Wild Animals FAMEV-UFU, were anesthetized with propofol at a dose of $10 \mathrm{mg} / \mathrm{Kg} / \mathrm{IV}$. The surgical technique consisted of skin incision in the cervical ventral median of about $4 \mathrm{~cm}$, removal of the muscles and ventral cervical trachea, incision on the ventral wall of the esophagus and continuous simple suture of the esophagus and muscles and simply separate the skin with absorbable sutures 3 - 0 chrome and nylon 3-0, respectively. Hemoglobin and packed cell volume were measured before and after surgery. The animals were weighed daily and the administration of enrofloxacin at a dose of $5 \mathrm{mg} / \mathrm{Kg} / \mathrm{IM} 3$ days after surgery. The removal of skin spots occurred with 16 days after surgery. It is concluded that the technique proposed here proved to be effective in its execution, and provided satisfactory recovery of the animals.
\end{abstract}

Keywords: esophagus, surgical technique, reptiles.

\section{INTRODUÇÃO}

A tartaruga-da-Amazônia (Podocnemis expansa) pertence ao reino Animalia, filo Chordata, subfilo Vertebrata, superclasse Tetrapoda, classe Reptilia, subclasse Anapsida e ordem Chelonia. Dentro da ordem dos quelônios, pertence à subordem Pleurodira, que são as espécies que retraem a 
cabeça e o pescoço lateralmente e se colocam sob a margem da carapaça, além de possuírem a pelve unida ao plastrão. Por fim, pertence à família Podocnemidae. (Reva et al., 1989)

No Brasil esta espécie habita rios e lagos dos Estados do Acre, Pará, Amazonas, Tocantins, Rondônia, Roraima, Amapá, Mato Grosso e Goiás. É o maior quelônio fluvial da América do Sul, atingindo em média $80 \mathrm{~cm}$ de comprimento de carapaça, $60 \mathrm{~cm}$ de largura de carapaça e peso médio de 60 kg. (Luz, 2005). Todavia, há indivíduos que chegam a $1 \mathrm{~m}$ de comprimento de carapaça. (Ernst e Barbour, 1989; Pritchard e Trebbau, 1984; Reva et al., 1989).

A espécie é de hábitos aquáticos, dependendo da água para o crescimento, alimentação, locomoção e acasalamento. Apenas a desova é feita fora da água, em covas nas praias dos rios. (Reva et al., 1989).

Os quelônios possuem bicos córneos que, além de usados para apreensão dos alimentos, funcionam como defesa. A mandíbula tem potente musculatura e quebra facilmente os alimentos. A língua é curta e firmemente aderida ao assoalho da boca, com a glote localizada posteriormente. As glândulas salivares produzem muco, mas não produzem enzimas digestivas. 0 estômago, intestino delgado, fígado, pâncreas e vesícula biliar produzem enzimas. Nos animais jovens, o ceco é pouco desenvolvido, aumentando de volume à medida que cresce. Isso sugere aumento na dieta vegetal ao longo do desenvolvimento. A parte final do tubo digestório termina na cloaca, composta pelo ânus e pelos orifícios urinário e genital. (Luz e Reis, 1999; Mader, 1996).

A tartaruga-da-Amazônia é um animal onívoro oportunista, predominantemente herbívoro. $O$ espectro de itens de que se alimenta é amplo e incluem frutos, flores, sementes, talos, raízes e folhas arbóreas e herbáceas, além de insetos, crustáceos, moluscos e peixes. (Luz, 2005).

Cágados em geral, ao se alimentarem, sofrem acidentes com anzóis, pedras, dentre outros corpos estranhos, que podem ficar presos no tubo esofágico e, então, podem apresentar a necessidade da realização de uma 
esofagotomia. Além disso, esta cirurgia é indicada em enfermidades como tumores, hérnia de hiato, refluxo esofágico, divertículo esofágico e motilidade anômala (Reva et al., 1989).

Podem ocorrer casos em que quelônios apresentam quadros de emaciação e/ou anorexia prolongada devido a uma cirurgia no trato gastrintestinal superior ou doenças que levem a quadros de afagia. Sendo necessário a colocação de um sonda gástrica no animal que podem causar trauma ou, no mínimo, estresse e desconforto. Devendo, então, se considerar a colocação de uma sonda esofágica. (Ernst e Barbour, 1989; Pritchard e Trebbau, 1984; Reva et al., 1989).

No intuito de se resolver quadros clínicos que obstruam o esôfago recorrem-se a métodos não cruentos como a passagem de sondas pelo tubo esofágico, que libera o esôfago do corpo estranho. Porém leva-o ao estômago, podendo causar um problema secundário neste órgão.

Portanto, um método eficiente para se retirar corpos estranhos, tumores, abscessos, e para se colocar sondas é a esofagotomia.

\section{MATERIAL E MÉTODOS}

Foram utilizados cinco cágados da espécie Podocnemis expansa Schweigger, 1812 de sexos e tamanhos variados, sendo a utilização destes animais para experimento, autorizada pelo IBAMA (Licença número 013/97DIFAS).

O procedimento experimental consiste em coletas de sangue, exames pré-cirúrgicos, anestesia, cirurgia, eletrocardiograma, exames pós-cirúrgicos, tratamento com antibiótico, retirada dos pontos, utilização de medicamentos tópicos, pesagens diárias e alimentação. Salvo um animal (quelônio 4) que precisou de antiinflamatório.Todos estes passos serão detalhados posteriormente. 
A pesagem do animal é feita diariamente, para o controle da saúde do mesmo. A primeira é feita no dia da cirurgia e continuam até a retirada dos pontos. O animal é pesado em uma balança comercial (Yara, Indústrias Vulcão S/A.

Os exames pré-cirúrgicos e pós-cirúrgicos foram realizados pelos mesmos métodos e com os mesmos materiais. Nestes exames foram medidos o volume globular (VG ou hematócrito) e a hemoglobina de cada animal. O exame pré-cirúrgico foi realizado no dia da cirurgia medindo os parâmetros do animal sadio. Os exames pós-cirúrgicos foram realizados com intervalo de 3 dias, sendo estes contados a partir do dia da cirurgia.

Todas as coletas de sangue foram feitas com a utilização de uma seringa de $3 \mathrm{ml}$, uma agulha $13 \times 4,5$, heparina e $1 \mathrm{ml}$ de sangue que foi retirado por punção caudal.

Para a determinação da hemoglobina foi utilizada a técnica do Hemoglobinômetro de Sahli, na qual se acrescenta ácido clorídrico N/10 no tubo graduado até a marca de $2 \mathrm{~g} \%$. Então, pipeta-se o sangue e coloca em tubo contendo ácido clorídrico a $10 \%$. Aspira-se o ácido e deixa o tubo em repouso por 10 minutos, para a hemoglobina ser reduzida a hematina ácida. Coloca-se então água destilada e agita-se com um bastonete. Continuar pondo água destilada gota a gota, até que a cor se iguale à do padrão. Faz-se, finalmente a leitura em gramas. O erro por esse método é de mais ou menos $10 \%$, devido a uma série de fatores.

Para a determinação do VG, utiliza-se, por leitura, um capilar, uma centrífuga de hematócrito, uma lamparina e sangue. Separados os materiais, o capilar é preenchido, por pressão negativa, até atingir $2 / 3$ (dois terços) de sua totalidade. Fecha-se a ponta livre de sangue do capilar com o auxílio do fogo da lamparina. Este capilar então é colocado na centrífuga de hematócrito por 5 minutos com $11000 \mathrm{rpm}$. Ao término da centrifugação, o capilar é retirado da centrífuga, dentro deste, o sangue fica separado em soro e hemáceas. Com o auxílio de um cartão de leitura de hematócrito é feita a leitura, colocando-se a borda superior do soro na linha superior do cartão e a borda inferior das 
hemáceas na linha inferior do cartão, para fazer a leitura observa-se a altura da separação entre soro e hemáceas, o valor correspondente a linha desta separação é o valor do VG, que é dado em porcentagem. Determinados os valores da hemoglobina e VG e o peso do animal no dia seguinte é feita a cirurgia.

Para a anestesia foi usado propofol, numa dose de $10 \mathrm{mg} / \mathrm{Kg} / \mathrm{EV}$. O anestésico foi colocado em um seringa de $3 \mathrm{ml}$ (volume superior a $1 \mathrm{ml}$ ) ou em uma seringa de $1 \mathrm{ml}$ (volume inferior a $1 \mathrm{ml}$ ) com uma agulha de $13 \times 4,5$. 0 medicamento foi injetado através do seio vertebral cervical proporcionado então uma anestesia geral no animal (Figura 1).

Para o eletrocardiograma foram feitas sucessivas leituras: inicialmente com o animal acordado (antes) e em seguida com 15, 30 e 45 minutos de anestesia, monitorando a anestesia e a freqüência cardíaca durante o decorrer da cirurgia (com média de uma hora de duração). Foi utilizado um eletrocardiógrafo (CMOS Drake, número de série CDN-00/035), gel para ultrasom e duas bobinas de papel para eletrocardiograma. $O$ animal foi conectado ao aparelho com quatro eletrodos do tipo jacaré na região caudal dos seus quatro membros e com uma agulha (eletrodo azul) introduzida na região ventral do plastrão na área do coração, sendo que o eletrodo vermelho foi conectado ao membro torácico direito, o preto ao membro pélvico direito, o amarelo ao membro torácico esquerdo e o verde ao membro pélvico esquerdo (Figura 2).

Esta disposição dos eletrodos é a mesma utilizada nos mamíferos domésticos. Utilizou-se a velocidade de $50 \mathrm{~mm} / \mathrm{s}$, derivação DIII e intensidade 1.

Após a anestesia iniciaram-se os procedimentos cirúrgicos no animal, sendo estes interrompidos rapidamente a cada 15 minutos para a realização de eletrocardiografia. A paramentação do cirurgião e do auxiliar foi feita dentro dos padrões convencionais, em seguida foi feita a anti-sepsia do local a ser operado (parte ventral do pescoço inteira) com polivinilpirrolidona-iodo oftálmico. Então com o auxílio de um cabo de bisturi número quatro e uma 
lâmina número 23, foi feita uma incisão com cerca de quatro centímetros (em média) na pele (Figura 3), em seguida foi feita a divulsão dos músculos da face ventral do pescoço com o auxílio de uma tesoura ponta fina, foi possível então observar a traquéia do animal (Figura 4). A traquéia foi afastada lateralmente (a esquerda) e finalmente o esôfago do animal foi localizado, assim como as artérias carótidas comuns esquerda e direita (Figura 5). Neste ponto da cirurgia o animal recebe um tubo esofágico, para o qual foi utilizada uma seringa de $1 \mathrm{ml}$ estéril. Após a intubação, seguem-se os procedimentos cirúrgicos, fazendo-se a incisão do esôfago de cerca de um centímetro e meio, em média (Figura 6). Após a incisão, inicia-se a sutura do órgão. Esta sutura é dada com o auxílio de um fio Categute Cromado 3-0 tipo $\mathrm{C}$ de $75 \mathrm{~cm}$, agulhado com agulha cilíndrica, cônica aguda, curva de $3,0 \mathrm{~cm}$ e com o auxílio de uma pinça anatômica. O padrão da sutura foi simples contínuo, com uma única linha de sutura (Figura 7). Ao término da sutura do órgão, o tubo esofágico é retirado e, com o mesmo tipo de fio usado na sutura deste, é feita a sutura da musculatura, seguindo o padrão simples contínuo (Figura 8). Finalizando, é feita a sutura de pele com fio de Nylon 3-0, monofilamentoso preto de $45 \mathrm{~cm}$, agulhado com agulha triangular, cortante, curva de $2,0 \mathrm{~cm}$ e com o auxílio de uma pinça anatômica, utilizando o padrão simples separado com quatro nós (Figura 9). Após o término da sutura de pele, a incisão, então suja de sangue, é limpa com o auxílio de uma compressa e soro fisiológico, após a limpeza é passado polivinilpirrolidona-iodo oftálmico para desinfecção da ferida. O animal era então colocado em um recinto fora d'água para a recuperação da anestesia.

Após o término da cirurgia o animal foi submetido a um tratamento com enrofloxacina na dose de $5 \mathrm{mg} / \mathrm{Kg}$, este tratamento foi feito durante três dias com uma aplicação por dia. As aplicações foram feitas intramusculares na região do membro torácico, alternando-se os lados. Foi utilizada uma seringa de $1 \mathrm{ml}$ e uma agulha $13 \times 4,5$, estéreis.

Os pontos foram retirados no $16^{\circ}$ dia após a cirurgia, com o auxílio de uma lâmina de bisturi número 23 e uma pinça anatômica. 
Após a retirada dos pontos, foi usado na ferida, Riodeíne Degermante ${ }^{R}$ (polivinilpirrolidona-iodo com láuril éter sulfato de sódio para desinfecção) e Alantol $^{\mathrm{R}}$, (cada $100 \mathrm{~g}$ contém dois gramas de Alantoína, $1 \mathrm{~g}$ de Clorexidine, $2 \mathrm{~g}$ de Óxido de zinco, 23,60g de Caulim, $14 \mathrm{~g}$ de Bentonita) medicamento de uso tópico cicatrizante. $\mathrm{E}$ os quelônios foram mantidos fora d'água durante 6 horas.

A alimentação das tartarugas é feita na água, com ração para gatos (Pachaly, 1992), banana, maçã, mandioca e abóbora cambotiá, sendo que estes alimentos eram oferecidos todos alternadamente. Nos quatro primeiros dias após a cirurgia, qualquer fruta ou vegetal oferecido deveria ser picado em pedaços miúdos e a ração de gato deveria ser amolecida em água primeiramente, picada e depois oferecida aos cágados. $O$ alimento era jogado na água e, os animais, o apanhavam na superfície.

No animal de número 4 foi administrado Banamine ${ }^{R} 10 \mathrm{mg} / \mathrm{ml}$ (Flunixin Meglumine), na dosagem de $2 \mathrm{mg} / \mathrm{Kg}$, durante dois dias com uma aplicação por dia, via intramuscular, na região do membro torácico, alternando-se os lados. Foi utilizada uma seringa de $1 \mathrm{ml}$ e uma agulha $13 \times 4,5$, ambos estéreis.

Ao término do experimento foi feita a análise estatística, somente com média simples, variância (que mede a dispersão dos dados em torno da média) e desvio padrão, devido o pequeno número de animais.

\section{RESULTADOS}

Os resultados deste experimento foram satisfatórios quanto ao problema e a hipótese, descritos previamente na introdução.

A recuperação dos quelônios quanto à alimentação foi boa, os animais voltaram a comer entre 8 a 10 dias após a cirurgia, sendo que todos os cinco animais submetidos à cirurgia não mostraram grande perda de peso, mantendo um padrão favorável. As pesagens foram feitas desde o dia da cirurgia (dia zero) até a retirada dos pontos ( $16^{\circ} \mathrm{dia}$ ). Como demonstrado no gráfico 1 . 


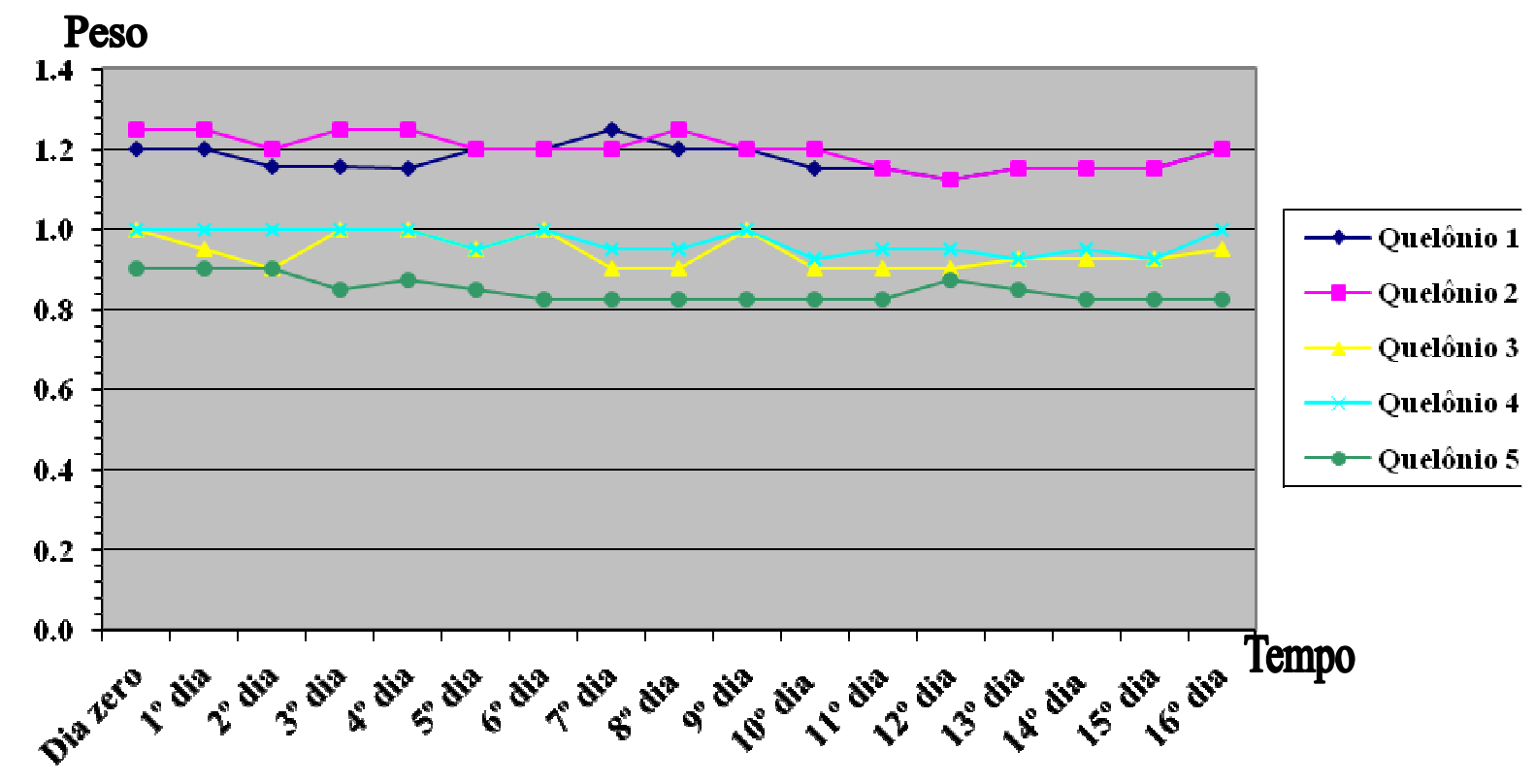

Gráfico 1 - Variação do peso $(\mathrm{Kg})$ em relação ao tempo (em dias) de póscirurgia.

Tabela 1 - Análise estatística da variação dos pesos (em $\mathrm{kg}$ ) dos quelônios. Uberlândia, 2003.

\begin{tabular}{lccccc}
\hline & Quelônio 1 & Quelônio 2 & Quelônio 3 & Quelônio 4 & Quelônio 5 \\
\hline Média & 1,25 & 1,27 & 1 & 1,03 & 0,9 \\
Variância & 0,0074 & 0,008 & 0,0056 & 0,0053 & 0,004 \\
Desvio & 0,086 & 0,09 & 0,075 & 0,072 & 0,063 \\
padrão & & & & & \\
\hline
\end{tabular}

Já os resultados dos exames pré e pós-cirúrgicos, foram obtidos através de quatro leituras, a primeira feita vinte e quatro horas antes da cirurgia, a segunda feita três dias após a cirurgia, a terceira realizada três dias após a segunda e a quarta, conseqüentemente, três dias após a terceira. Nestes exames, obteve-se o valor do VG e da hemoglobina dos cinco animais anteriormente mencionados. Foram observados os seguintes valores para a hemoglobina. 


\section{Valores de hemoglobina}

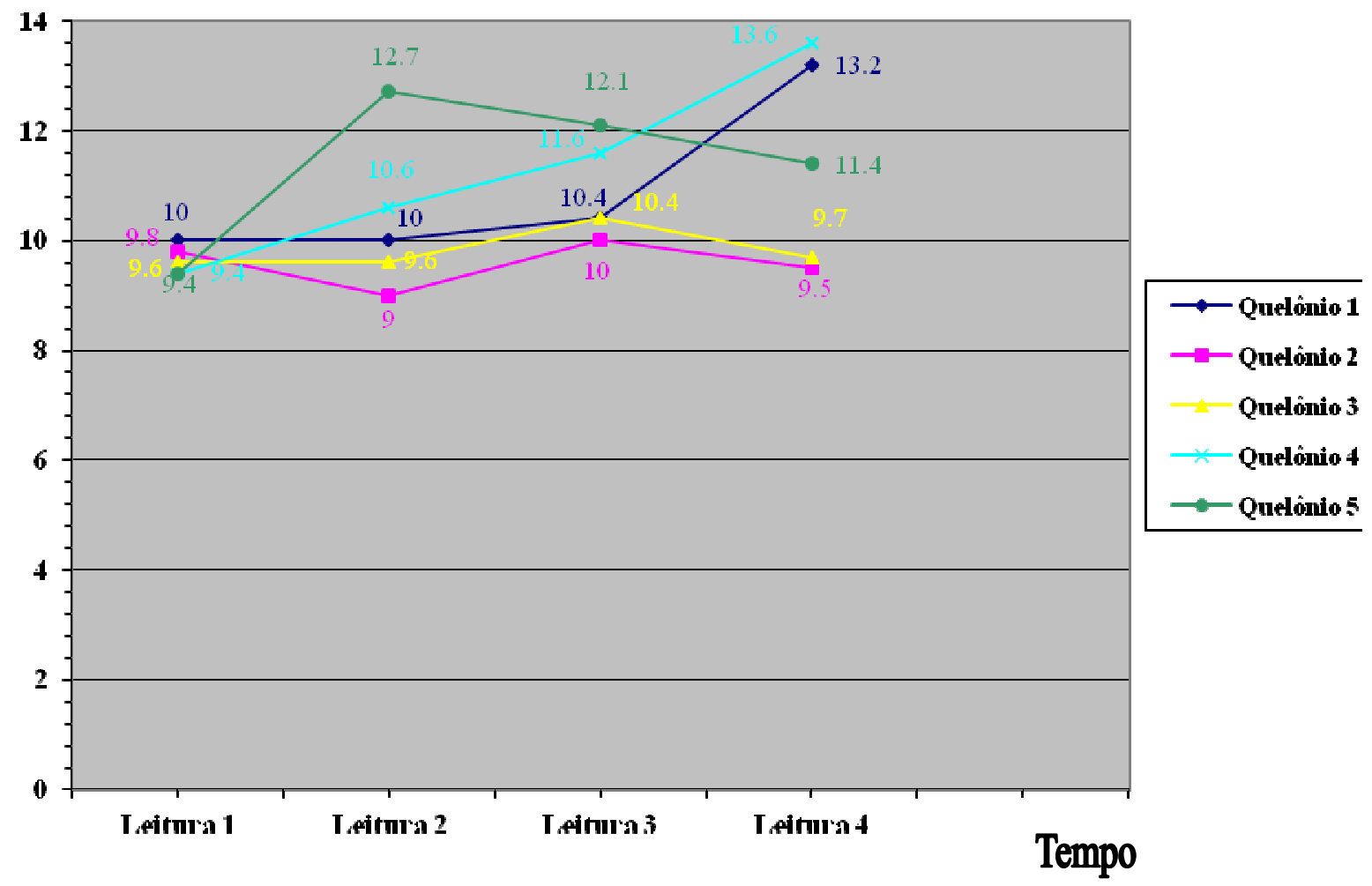

Gráfico 2 - Variação dos valores da hemoglobina em relação às leituras 1, 2, 3 e 4, com intervalos de 3 dias entre as mesmas.

Tabela 2 - Análise estatística dos resultados das leituras de hemoglobina ( $\mathrm{g} \%$ ) dos quelônios. Uberlândia, 2003.

\begin{tabular}{lccccc}
\hline & Quelônio 1 & Quelônio 2 & Quelônio 3 & Quelônio 4 & Quelônio 5 \\
\hline Média & 10,15 & 9,6 & 9,8 & 11,05 & 11,65 \\
Variância & 0,04 & 0,2 & 0,15 & 2,4 & 1 \\
Desvio & 0,6 & 0,44 & 0,4 & 1,55 & 1 \\
padrão & & & & & \\
\hline
\end{tabular}


Os seguintes resultados das leituras do VG foram obtidos.

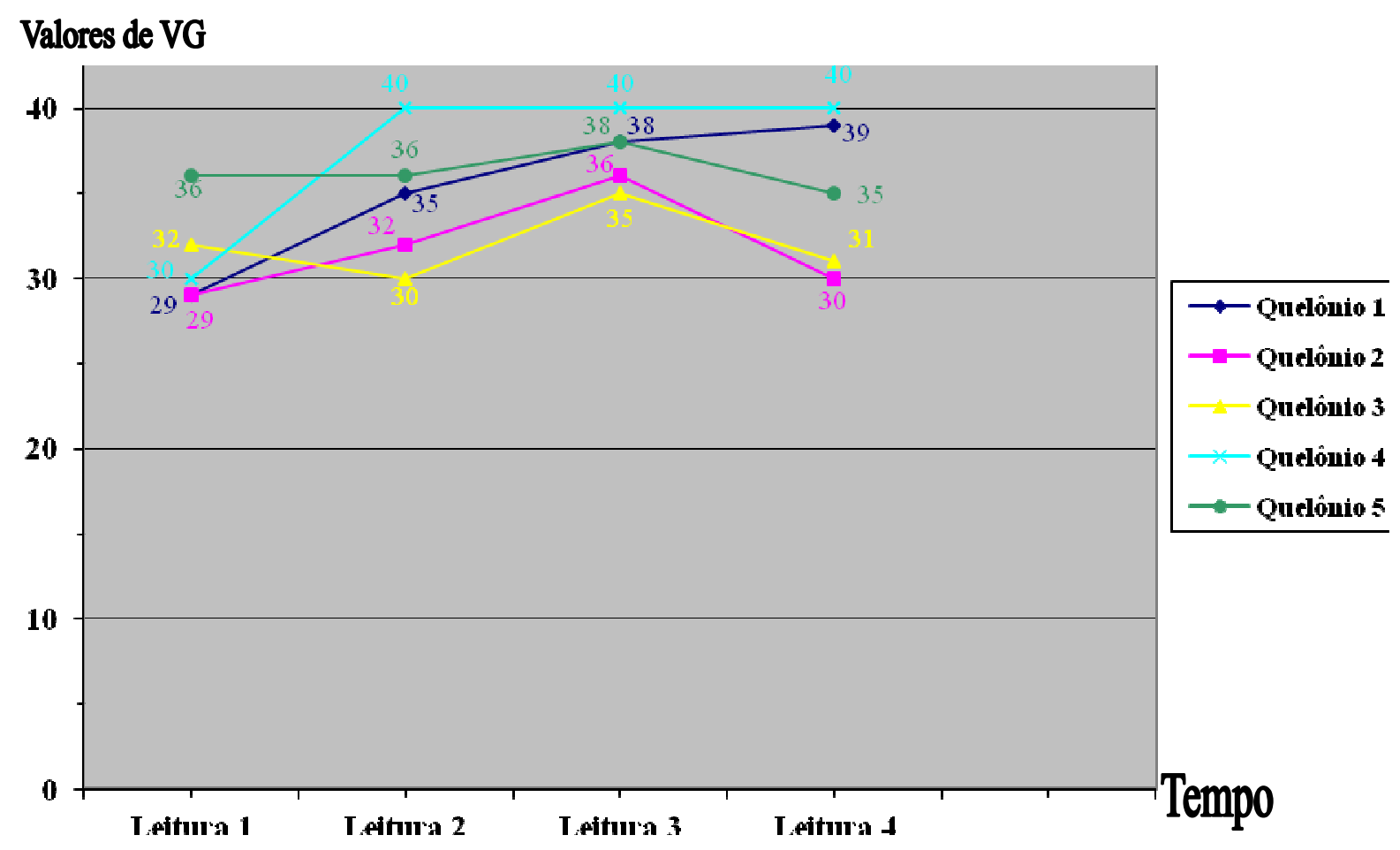

Gráfico 3 - Variação dos valores do VG em relação ao tempo, com intervalo de 3 dias entre cada leitura.

Tabela 3 - Análise estatística dos resultados das leituras do VG (\%) dos quelônios. Uberlândia, 2003.

Quelônio 1 Quelônio 2 Quelônio 3 Quelônio 4 Quelônio 5

\begin{tabular}{lccccc}
\hline Média & 34,25 & 31,75 & 32 & 37,5 & 36,25 \\
Variância & 14,25 & 9,6 & 4,7 & 25 & 1,6 \\
Desvio & 3,78 & 3,1 & 2,2 & 5 & 1,26 \\
padrão & & & & & \\
\hline
\end{tabular}

Com relação à anestesia com Propofol $(10 \mathrm{mg} / \mathrm{Kg} / \mathrm{EV})$, obteve-se como resultado uma analgesia completa, ou seja, o animal não apresentava reflexos 
e nem resposta à dor, sendo possível realizar a esofagotomia, a qual durou cerca de uma hora para cada animal. A via de aplicação era de difícil acesso, sendo importante o conhecimento sobre a anatomia vascular do pescoço da Podocnemis expansa (Schweigger, 1812), necessitando-se muito treino e prática.

Os resultados do eletrocardiograma estão expressos na tabela 4.

Tabela 4 - Média dos batimentos cardíacos por minuto, antes e 15, 30, 45 minutos após administração de propofol E.V. $10 \mathrm{mg} / \mathrm{Kg}$ em Podocnemis expansa.

\begin{tabular}{lcccc}
\hline \multirow{2}{*}{ Quelônio } & Tempo & $(\mathrm{min})$ & pós & administração \\
\cline { 2 - 5 } & antes & $15 \mathrm{~min}$ & $30 \mathrm{~min}$ & $45 \mathrm{~min}$ \\
\hline 1 & 14,9 & 30,6 & 30 & 30 \\
2 & 30,2 & 28,3 & 24,1 & 25,2 \\
3 & 24 & 31,9 & 33,7 & 34 \\
4 & 21,2 & 33,3 & 32,2 & 30,6 \\
5 & 33,3 & 31,5 & 31,5 & 28,3 \\
\hline
\end{tabular}

A esofagotomia cervical realizada nos cágados da espécie Podocnemis expansa Schweigger, 1812 respondeu aos padrões esperados. Em relação à anti-sepsia realizada no local da operação, obteve-se uma desinfecção satisfatória, pois não houve inflamação da ferida devido a contaminações. As incisões foram realizadas de maneira simples e sem dificuldades, porém foi preciso deixar a pele bem tracionada, devido às rugosidades da mesma. 0 sangramento da pele foi insignificante, não apresentando preocupações ao cirurgião. Foi então feita a divulsão dos músculos do pescoço. O sangramento é mínimo, também não apresentando perigo e a divulsão não apresenta nenhuma complicação. Ao visualizar a traquéia, esta foi desviada lateralmente (para esquerda) com muita delicadeza para que não ocorresse rompimento da mesma, não causando nenhuma deformidade ao órgão, sendo possível, 
visualizar o esôfago e as artérias carótidas comuns direita e esquerda. O tubo esofágico é inserido com cuidado, sendo que neste caso, foi utilizada uma seringa estéril de $1 \mathrm{ml}$, pois esta possuía um diâmetro compatível com o do esôfago e facilitava a realização da incisão e sutura do órgão. Com o tubo colocado é feita a incisão do esôfago, apoiando o corte do bisturi todo no tubo esofágico, o sangramento é insignificante e a incisão não apresenta dificuldades maiores. A sutura do órgão de padrão simples contínuo e o fio utilizado foram satisfatórios, devido ao fato dos animais manterem a alimentação, não desenvolvendo sinais de afagia, mostrando que não houve aderência no lúmen do órgão, pois os animais conseguiam deglutir. O tubo foi retirado, sem algum problema e as suturas de musculatura e pele obtiveram bons resultados observados. A sutura da pele era difícil, pois a pele do cágado é muito elástica e rugosa (principalmente a do pescoço), daí para auxiliar na sutura da pele, foi utilizada uma pinça anatômica para que a introdução da agulha na pele fosse facilitada. A limpeza da pele somente com soro fisiológico e a desinfecção da ferida com polivinilpirrolidona-iodo oftálmico foram suficientes, pois quase não houve sangramento.

O tratamento com enrofloxacina na dose de $5 \mathrm{mg} / \mathrm{Kg}$ IM, a cada 24 horas, durante três dias teve um resultado bom, pois nenhum animal apresentou inflamações nas feridas e nem sintomas de contaminação.

A retirada dos pontos havia sido estimada no $12^{\circ}$ dia após a cirurgia, porém houve uma tentativa de retirada nos quelônios 1 e 2 e as feridas ainda se mostravam com cicatrização incompleta (Figuras 10 e 11), tanto que nos quelônios 3, 4 e 5, nem foi feita esta tentativa. Então, uma nova data foi estipulada, sendo esta feita no $16^{\circ}$ dia após a cirurgia. Estando, então, a cicatrização completa (Figuras 12, 13, 14, 15 e 16). A desinfecção da ferida após remoção dos pontos, aplicação de medicamento tópico e o fato dos animais terem ficado 6 horas fora d'água, contribuiu para a secagem da ferida. Depois de colocados na água novamente, estes não foram mais retirados e a cicatriz continuava com o mesmo aspecto. 
Uma alteração que merece destaque, foi o quadro desenvolvido pelo quelônio 4, que após a cirurgia, não conseguia submergir na água. 0 diagnóstico provisório foi de enfisema pulmonar, porém não foi confirmado. $O$ animal foi tratado com Banamine ${ }^{R} 10 \mathrm{mg} / \mathrm{Kg}$ (Flunixin Meglumine), na dosagem de $2 \mathrm{mg} / \mathrm{Kg}$, durante dois dias com uma aplicação por dia. No entanto, não foram mostrados sinais de melhora do quadro. O animal se alimentava normalmente, apresentava-se alerta e tentava fugir quando capturado. Não apresentava perda de peso, o VG e hemoglobina apresentavam os valores mais altos de todos os cinco quelônios.

\section{DISCUSSÃO}

Shuttleworth e Smythe (1966), ao descrever a técnica da esofagotomia em cães, relataram que se faz a elevação do esôfago com uma pinça e o secciona com um bisturi. Porém neste experimento com Podocnemis expansa Schweigger, 1812, foi feita, antes da incisão do órgão, a sondagem do animal. $\mathrm{O}$ que pode ser feito também em qualquer outra espécie, sendo a técnica que utiliza a sondagem mais segura, pois não permite que se incida o lado oposto do órgão. E também não há necessidade de elevá-lo com uma pinça, o que resulta num manuseio menor do órgão.

Dietz et al. (1979) sobre a sutura do órgão, informam que a mucosa se fecha com uma sutura de seda fina segundo a técnica de Schimieden, na qual os nós se encontram situados na luz esofágica. Para finalizar, pratica-se sobre esta e através da submucosa e muscular, uma segunda linha de sutura de acordo com Schimieden com catgut cromado fino, que invaginará a primeira linha de sutura. Anderson (1980) afirma que a incisão da esofagotomia é fechada por suturas na mucosa, com uma outra camada de sutura separada na camada muscular. Bojrab (1990) descreve a sutura do esôfago de maneira que a mucosa e a submucosa são fechadas por pontos simples separados com os nós dentro do lúmen. A segunda linha de sutura é feita com pontos simples separados na camada muscular. Embora muitos tipos de materiais de sutura 
tenham sido defendidos para se fechar o esôfago, o autor recomenda o 2-0 ou 3-0 polidiaxinona (PDS). Porém, neste experimento com os quelônios, foi constatado que uma só linha de sutura, simples contínua, com fio Categute Cromado 3-0 tipo C, foi suficiente e não provocou nenhuma reação indesejada.

Bojrab (1990) referindo-se à técnica da esofagotomia, descreve que o músculo é retraído lateralmente expondo a traquéia, a qual é então firmada à direita. Na técnica realizada neste experimento com Podocnemis expansa a traquéia foi firmada a esquerda, com cuidado para que não ocorresse perfuração da mesma, o que não provocou alteração da cirurgia e da recuperação do animal.

Vanclooster et al. (1989) relatam que o problema do pós-operatório pode ser a fistula e formação de abscesso após a cirurgia e pode ser evitado por técnicas corretas, exclusão da patologia implícita, uma drenagem adequada e conseqüente tratamento de infecções. Em Podocnemis expansa, não ocorreram nenhum dos problemas citados acima e não houve necessidade de realizar dreno cirúrgico.

Frye (1991) descreve que, quanto aos padrões de sutura, no fechamento de incisões cirúrgicas em répteis, o padrão de sutura e sua colocação depende do procedimento, da espécie de réptil e do ambiente no qual o animal irá ser mantido durante sua recuperação. Suturas contínuas são mais fáceis de serem feitas e retiradas, salvando muito do tempo do cirurgião, mas há sempre um risco da ferida ser prejudicada se houver qualquer dano à sutura. Suturas simples separadas, com no mínimo três nós, oferecem uma grande segurança na sutura, mas em algumas áreas anatômicas que não há contato com substratos abrasivos, um padrão contínuo é preferido. Um padrão contínuo é particularmente proveitoso quando se necessita suturar incisões na pele da fossa ao redor dos membros dos quelônios. O padrão de sutura de pele em Podocnemis expansa neste experimento, foi simples separado com quatro nós, com fio de Nylon 3-0, monofilamentoso preto, o que segue o relato acima, que suturas simples separadas são mais seguras, principalmente na região do pescoço, pois foi observado, que mesmo antes da retirada dos pontos com 16 
dias, alguns pontos já haviam caído, o que seria um transtorno se o padrão fosse contínuo, tal ocorrência pode ser observada nas figuras 14, 15, e 16.

Frye (1991) ainda comenta que geralmente, o procedimento preferencial para se iniciar a sutura de pele se dá com a primeira sutura no centro da incisão ou laceração, e então se trabalha em direção das extremidades do corte. Esta técnica ajuda a prevenir franzimento das beiradas da ferida e promove cicatrização mais rápida e sem complicações. Tal procedimento não ocorreu na Podocnemis expansa, sendo todas as suturas realizadas sempre da esquerda para a direita, o que não provocou alterações indesejáveis e nem dificuldade para suturar.

Frye (1991) ainda comenta que na maioria das circunstâncias, tartarugas aquáticas e semi-aquáticas devem ter acesso e exposição limitadas à água; elas devem ser colocadas na água diariamente para se alimentarem e se hidratarem, porém elas não devem ser deixadas na água continuamente. Neste trabalho realizado com Podocnemis expansa, os animais foram deixados de fora d'água somente para se recuperarem da anestesia durante cerca de 8 horas e após retirada dos pontos durante 6 horas, o restante do tempo os quelônios eram mantidos o tempo todo dentro d'água e a cicatrização da pele se deu satisfatoriamente com 16 dias.

Mader (2006) comenta sobre tartarugas marinhas doentes e feridas, onde afirma que elas devem ser monitoradas de perto através de perfis sanguíneos, consumo de alimentos, peso corpóreo e observação de atividade e defecação durante as primeiras semanas de convalescença, ou até que a condição das tartarugas se mostre estável. O que foi proposto por Mader, foi feito neste experimento com quelônios dulcícolas.

Torsoni et al. (2002) relatam que o hematócrito da tartaruga Geochelone denticulata foi de $32 \%$, estando dentro dos parâmetros encontrados neste experimento com Podocnemis expansa. 
SANTOS, A.L.Q. et al. Esofagotomia cervical em Tartaruga-da-Amazônia Podocnemis expansa Schweigger, 1812 (Testudines - Podocnemididae). PUBVET, Londrina, V. 6, N. 11, Ed. 198, Art. 1329, 2012.

\section{CONCLUSÕES}

A técnica proposta mostrou-se eficaz, sendo sua execução realizada sem complicações tanto para o animal quanto para o cirurgião.

A recuperação dos quelônios mostrou-se sem alterações preocupantes no peso, hemoglobina e VG.

Os animais voltaram às suas atividades normais, sem nenhuma seqüela pós-operatória.

\section{REFERENCIAS BIBLIOGRÁFICAS}

BOJRAB, M. J. Current techniques in small animal surgery. Philadelphia: Lea \& Febinger, 3 ed, 1990. p.201-205.

DIETZ, O.; SCHAETZ, F.; SCHLEITER, H.; TEUSCHER, R. Operaciones y anestesia de los grandes y pequeños animales. Zaragozaa: Acribia, 2 ed, 1979. p. 238-241.

ERNST, C.H.; BARBOUR, R.W. Turtles of the world. Washington and London: Smithsonian Institution, 1989. $313 \mathrm{p}$.

FRYE, F. L. Reptile Care - An atlas of diseases and treatments. Neptune City: T. F. H. Publications, v.1-2, 1991. p. 181, 205, 476, 443-445.

LUZ, V.L.F.; REIS, I.J. Conservação e criação comercial de quelônios. Goiânia: CENAQUA, 1999. 3

LUZ, V.L.F. Criação comercial de tartaruga e tracajá - Manual técnico. Cuiabá: SEBRAE, 2005. $72 \mathrm{p}$.

MADER, D.R. Reptile medicine and surgery. Philadelphia: W.B. Saunders Company, 1996. $512 \mathrm{p}$.

MADER, D.R. Reptile medicine and surgery. Philadelphia: W.B. Saunder Company, 2ed,2006. p.275, 334, 425, 434.

PRITCHARD, P.C.H.; TREBBAU, P. The turtles of Venezuela. Society for the Study of Amphibians and Reptiles, 1984. 403 p.

ReVA, E.; BALENSIEfer, M.; SILVA, R.H.B. Projeto Quelônios da Amazônia 10 anos. Brasília:

SHUTTLEWORTH, A. C.; SMYTHE, R. H. Clinica quirurgica veterinaria. México: Compañia Editorial Continental S.A., 2 ed, v. 2, 1966. p. 245-249.

TORSONI, M. A.; STOPPA, G. R.; TURRA, A.; OGO, S. H. Functional behavior of tortoise hemoglobin Geochelone denticulata. 
VANCLOOSTER P.; VAN RAEMDONCK D.; LERUT T.; GRUWEZ J. Surgery of foreign bodies in the esophagus in case of failure of noninvasive extraction technics. Disponível em: < http://gateway.nlm.nih.gov/gw/Cmd?GMResults> Acesso em: 15 jan. 2012. 